\title{
Comparison of Wideband vs Narrowband Acoustic Approach to Target Strength Value on Bullet Tuna (Auxis rochei) and Bonito (Euthynnus affinis)
}

\author{
W. Setiawan, I. Jaya, T. Hestirianoto and S. Pujiyati \\ Dept. Marine Science \& Technology, IPB University, Indonesia.
}

\author{
A. Priatna and A. Ma'mun \\ Marine Fisheries Research Center, Ministry of Marine and Fisheries Affairs, Indonesia.
}

(Received 18 June 2019; accepted 3 October 2019)

\begin{abstract}
Target strength $(T S)$ is one of the main parameters for determining fish density, abundance and biomass in acoustic technique. Therefore, it is of utmost importance to obtain an accurate $T S$ estimate and to minimize bias from its measurement. Various factors contribute to bias in acoustic $T S$, namely the high diversity of species, body shape, size and also frequencies used. In this paper we compare and examine the acoustic narrowband (NB) and wideband (WB) approaches to better understand the $T S$ response to various frequencies. The use of acoustic wideband approach, is expected to perform better and be less-biased than the narrowband, which is still widely used. The measurement of bullet tuna (Auxis rochei) and bonito (Euthynnus affinis) for the same fork length $(F L)$ size showed the power of four frequency dependent $\left(f^{4}\right)$. Furthermore, a comparison between NB frequency of $200 \mathrm{kHz}$ versus WB at the nearby frequencies of $190-200 \mathrm{kHz}$ and $200-210 \mathrm{kHz}$ showed a significant Pearson correlation value for bonito fish size range from $17-26.6 \mathrm{~cm}$, whereas in the case of bullet tuna, fish had no significant correlation at $\alpha=0.05$ for fish size range from $16.4-26 \mathrm{~cm}$.
\end{abstract}

\section{INTRODUCTION}

The embodiment of sustainable fisheries management where exploitation levels are balanced with the rate of recovery and growth of fish resources requires adequate information support on the condition or status of fish stock resources. Goddard and Welsby indicated that one of the key pieces of information that needs to be known in determining a realistic, measurable, and objective evaluation of fisheries management measures is the initial description of the fish stock condition that serves as the starting point of reference. ${ }^{1}$ Given this starting point of reference, the effectiveness of management actions that have been and will be taken can be determined with a high level of confidence. Various efforts have been made to provide the aforementioned data and information by conducting surveys of fish stocks using the acoustic technique (Johanesson and Mitson) ${ }^{2}$ and catch sampling (Harbitz, et al.), ${ }^{3}$ as well as recording catch data at ports (FAO/SEAFDEC). ${ }^{4}$

Simmonds and MacLennan have found that accuracy and confidence of the acoustic technique estimate of fish stock assessment are strongly dependent on the accuracy of measured values of fish acoustic target strength $(T S) .^{5}$ This is very important because $T S$ is the main parameter for determining fish density, abundance and biomass in acoustic technique applications.

Traditionally, NB echosounders, transmitting singlefrequency sinusoidal pulses, also referred to as continuous wave $(\mathrm{CW})$ tones, have been extensively used for fisheries research over four and a half decades (Holliday, Foote, et al.,
Komeliussen and Ona, Scoulding, et al.). ${ }^{6-9}$

However, there has been a recent emergence of WB acoustic backscattering systems transmitting frequency modulated (FM) signals, typically linearly-frequency modulated signals, or chirps, for characterizing fish and other marine organisms (Foote, et al. and Stanton, et al.). ${ }^{10,11}$ The promising success of this WB system was built on a wide history of laboratory based WB and in situ measurements (Holliday, Simmond and Amstrong, Stanton, et al., Thompson and Love, Zakharia, et al.). ${ }^{6,12-15}$

The WB system enables measurements of backscattering acoustics to be measured continuously within the range of the frequency range, thereby increasing the amount of information available for target spectral characterization, as compared to the NB technique, which measures acoustic backscatter at discrete frequencies.

Lavery, et al. explained the term WB refers to systems that use FM transmit signals and hardware capable of transmitting and receiving over a wide range of frequencies. ${ }^{16} \mathrm{WB}$ transducers usually increase in line with the frequency of the used transducer. The term WB refers to a system that combines multiple transducers, each with different WB or NB signals and capabilities, to span a range of frequencies larger than that which can be achieved with a single transducer. The improvements associated with WB signal processing techniques cannot be achieved from a collection of NB signals. The goal of this study is to examine the acoustic WB approach to better understand the $T S$ response to various frequencies. This is the 


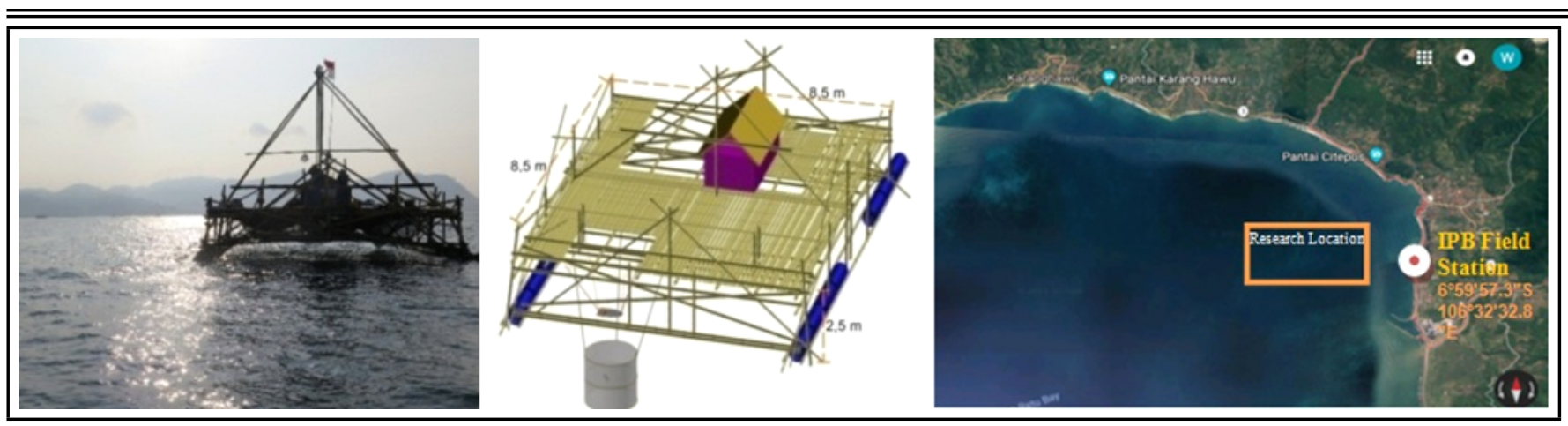

Figure 1. Lift net floating platform and location of the field measurements.

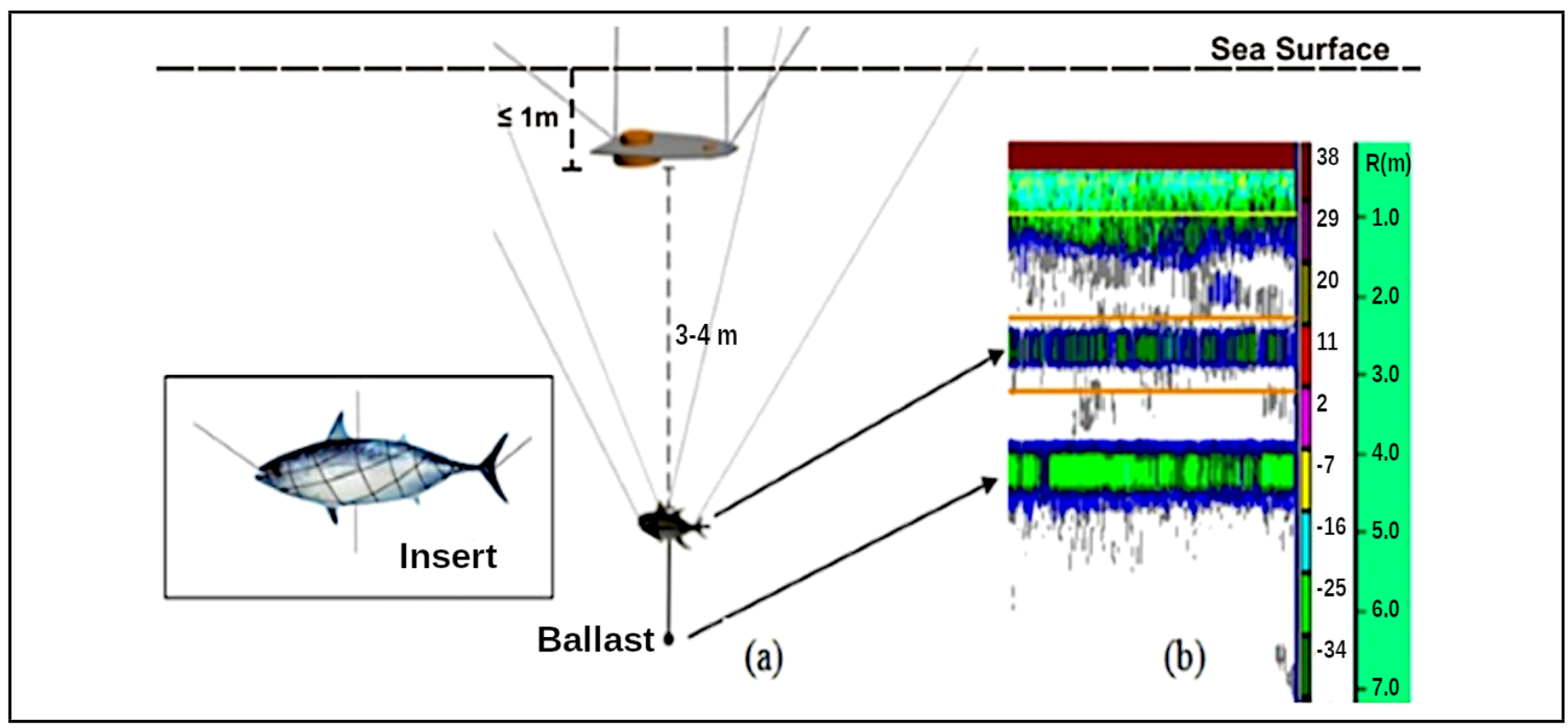

Figure 2. (a) Measurement of $T S$ fish by tethered method. (b) An example of the measurement echogram of $T S$ bullet tuna, the target fish clearly visible apart with the ballast (ca. $0.5 \mathrm{~kg}$ marble stone) and other objects.

initial attempt to produce fingerprints (signature) of the target fish studied, in this case bullet tuna (Auxis rochei) and bonito (Euthynnus affinis) to enhance targets identification.

\section{RESEARCH METHODS}

Acoustic TS measurements on bullet tuna (Auxis rochei) and bonito (Euthynnus affinis) with NB and WB approaches were conducted using a lift net floating platform (Fig. 1) in Palabuhanratu Bay waters in September 2017.

A scientific echo sounder Simrad EK 80 with $200 \mathrm{kHz}$ split beam transducer, sphere ball (target standard) type tungsten carbide (WC) diameter $38.1 \mathrm{~mm}$, CTD SBE 19 plus for measuring temperature and salinity were used during the acoustic $T S$ measurement. Prior to performing the $T S$ measurement activity, the acoustic system was first calibrated using the sphere ball that was placed at a depth of $4.5 \mathrm{~m}$ from the surface of the transducer. The parameter settings used during calibration were: single frequency $\mathrm{CW} 200 \mathrm{kHz}$; frequency of WB FM 160 - $240 \mathrm{kHz}$; pulse duration $0.512 \mathrm{~ms}$; transmit power $150 \mathrm{~W}$; water speed sound $1542 \mathrm{~m} / \mathrm{s}$; absorption coefficient $82.9 \mathrm{~dB} / \mathrm{km}$; temperature $29.3^{\circ} \mathrm{C}$; salinity $32.70 \mathrm{ppt}$; $\mathrm{pH} 8.1$; and $S V$ (scattering volume) and $T S$ threshold of $-60 \mathrm{~dB}$ and was used at the time of acquisition of the $T S$ value of each
Table 1. Size range of fish samples used in the measurement.

\begin{tabular}{|c|c|c|c|c||}
\hline No. & Fish sample & $\begin{array}{c}\text { Fork length } \\
(F L), \mathrm{cm}\end{array}$ & Fish sample & $\begin{array}{c}\text { Fork length } \\
(F L), \mathrm{cm}\end{array}$ \\
\hline 1 & Bt 01 & 16.4 & Bo 01 & 17 \\
2 & Bt 02 & 17.5 & Bo 02 & 18 \\
3 & Bt 03 & 17.6 & Bo 03 & 18.5 \\
4 & Bt 04 & 19.5 & Bo 04 & 20 \\
5 & Bt 05 & 19.5 & Bo 05 & 20.5 \\
6 & Bt 06 & 20.4 & Bo 06 & 22 \\
7 & Bt 07 & 20.6 & Bo 07 & 25.5 \\
8 & Bt 08 & 20.7 & Bo 08 & 25.5 \\
9 & Bt 09 & 21 & Bo 09 & 26 \\
10 & Bt 10 & 25.6 & Bo 10 & 26.5 \\
11 & Bt 11 & 26 & & \\
\hline
\end{tabular}

individual fish. Water temperature and salinity measurements were performed with SBE 19 plus to obtain the speed of sound. Fish used in the study were 11 samples of dead bullet tuna (Auxis rochei) (Bt) and 10 samples of dead bonito (Euthynnus affinis) (Bo) as shown in Table 1. In this study we used dead fish, but in a previous study it was stated that the live fish $T S$ value did not have a significant difference from dead fish value for torpedo scad (Megalaspis cordyla) for in situ measurement (Setiawan, et al.). ${ }^{17}$ 


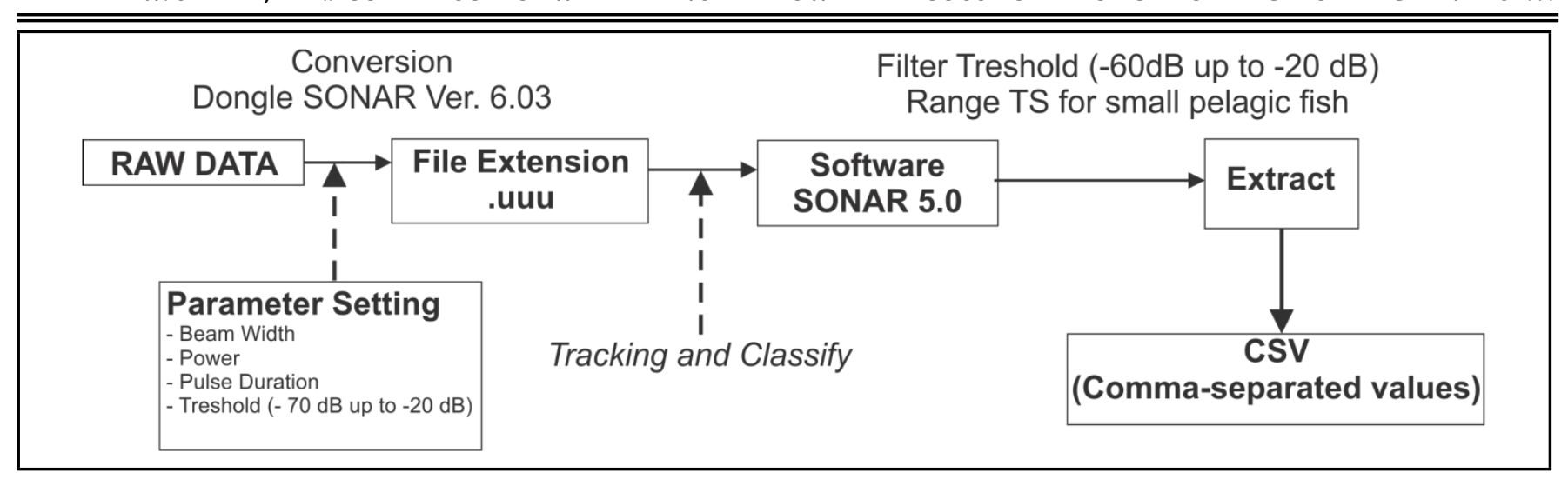

Figure 3. Flow chart acoustic data acquisition.

\section{METHODS AND DATA ANALYSIS}

\subsection{Measurement of $T S$ Value}

Measurements of acoustic $T S$ of fish were conducted using tethered techniques, where each fish was positioned horizontally and suspended from on a monofilament strings-woven net (see Fig. 2). Each individual fish was insonified with an acoustic pulse, where the transducer was placed over a hanging fish sample so that the target (fish) was in the acoustic beam area (Simmond and MacLenan). ${ }^{5}$ The echo sounder parameter settings used at the time of acquisition must conform to the setting of parameters at calibration time. The $T S$ measurements for each fish samples were taken over approximately one hour with the transmission of data for one frequency treatment of about 5-8 minutes. Data collection was carried out during the day, between 08:00 am to 05:00 pm under calm to small waves weather conditions. Data acquisition flow chart is shown in Fig. 3.

\subsection{Data Analysis}

The acoustic data were extracted using SONAR 5-pro software. The extraction results were presented as $T S$ values in decibels $(\mathrm{dB})$. The $T S$ value of each individual fish measured by acoustics consisted of many variations of $T S$ values that spread within a certain range, but generally were spread normally and had a certain mode value.

The $T S$ value was defined as:

$$
T S=10 \log _{10}\left(\sigma_{b s}\right)
$$

where $\sigma_{b s}$ was a measured backscattering cross section from a single target. The linear TS measurements were used to compute mean $T S$,

$$
\text { Mean } T S=10 \log _{10}\left(\frac{1}{N} \sum_{i=1}^{N} 10^{T S i_{i} / 10}\right) ;
$$

where $N$ was the number of pings data collection for one fish.

\section{3. $T S$ Value of Each Individual Fish and Sphere Ball Calibration}

The amount of data used to obtain the average $T S$ value of a single individual fish was the $T S$ data in the range of $\pm 3 \mathrm{~dB}$ from the peak value of the mode class. The $T S$ was a backscattering cross section $\left(\sigma_{b s}\right)$ of the returned target signal, the relationship between $T S$ and $\sigma_{b s}$ was expressed as in Eq. (1) and the average as in Eq. (2). The average $T S$ value was assumed to be the $T S$ value of each individual fish. Calculation of the $T S$ fish was treated with measurement with a different type of signal used, for a single frequency (CW) $200 \mathrm{kHz}$ frequency was used, while for signal WB (FM) using the frequency of $160-240 \mathrm{kHz}$ with the sorting of frequency interval every $10 \mathrm{kHz}$. WC $38.1 \mathrm{~mm}$ ball sphere TS value modeling is shown in Fig. 4.

\section{RESULTS AND DISCUSSION}

\subsection{Target Strength Value}

The TS measurements were performed on 21 fishes of the Scombridae family, consisting of 11 samples of bullet tuna (Auxis rochei) that ranged from $16.4-26 \mathrm{~cm}$ in length and 10 samples of bonito (Euthynnus affinis) of $17-26.5 \mathrm{~cm}$ in size measured in whole circumstances deceased condition (Table 2). However, the only thing that will be discussed in this paper is the shift of the $T S$ values of two different fish species but with the same fork length of $26 \mathrm{~cm}$ (sample numbers 11 and 09 in Table 1)

The $T S$ calculation values of both samples were treated with 9 different frequency band signals, as follows: 1) Single frequency $200 \mathrm{kHz}$; 2) $\mathrm{FM}$ frequency $160-170 \mathrm{kHz}$; 3) FM frequency $170-180 \mathrm{kHz}$; 4) FM frequency $180-190 \mathrm{kHz}$; 5) $\mathrm{FM}$ frequency $190-200 \mathrm{kHz}$; 6) FM frequency $200-$ $210 \mathrm{kHz}$; 7) FM frequency $210-220 \mathrm{kHz}$; 8) FM frequency $220-230 \mathrm{kHz}$; and 9) FM frequency $230-240 \mathrm{kHz}$. The $T S$ values of each treatment were compared with the $T S$ values obtained from the tungsten carbide sphere of $38.1 \mathrm{~mm}$ calibration results as shown in Table 2. The purpose of calibration using spheres was to obtain absolute $T S$ values that can be used for comparison against other measurements (Simmond and MacLenan). ${ }^{5}$ Samples of $F L=26 \mathrm{~cm}$ bullet tuna (Auxis rochei) had $T S_{\max }=-43.17 \mathrm{~dB}$ value at FM $170-180 \mathrm{kHz}$ and $T S_{\min }=-47.97$ at FM $230-240 \mathrm{kHz}$ frequency signal. The sample of bonito (Euthynnus affinis), for the same size showed $T S_{\max }=-32.59 \mathrm{~dB}$ value at FM $220-230 \mathrm{kHz}$ and $T S_{\min }=-51.49 \mathrm{~dB}$. For sphere it was $T S_{\max }$ value $-38.89 \mathrm{~dB}$ at the single frequency $200 \mathrm{kHz}$ and $T S_{\min }-60.83$ 
(a)

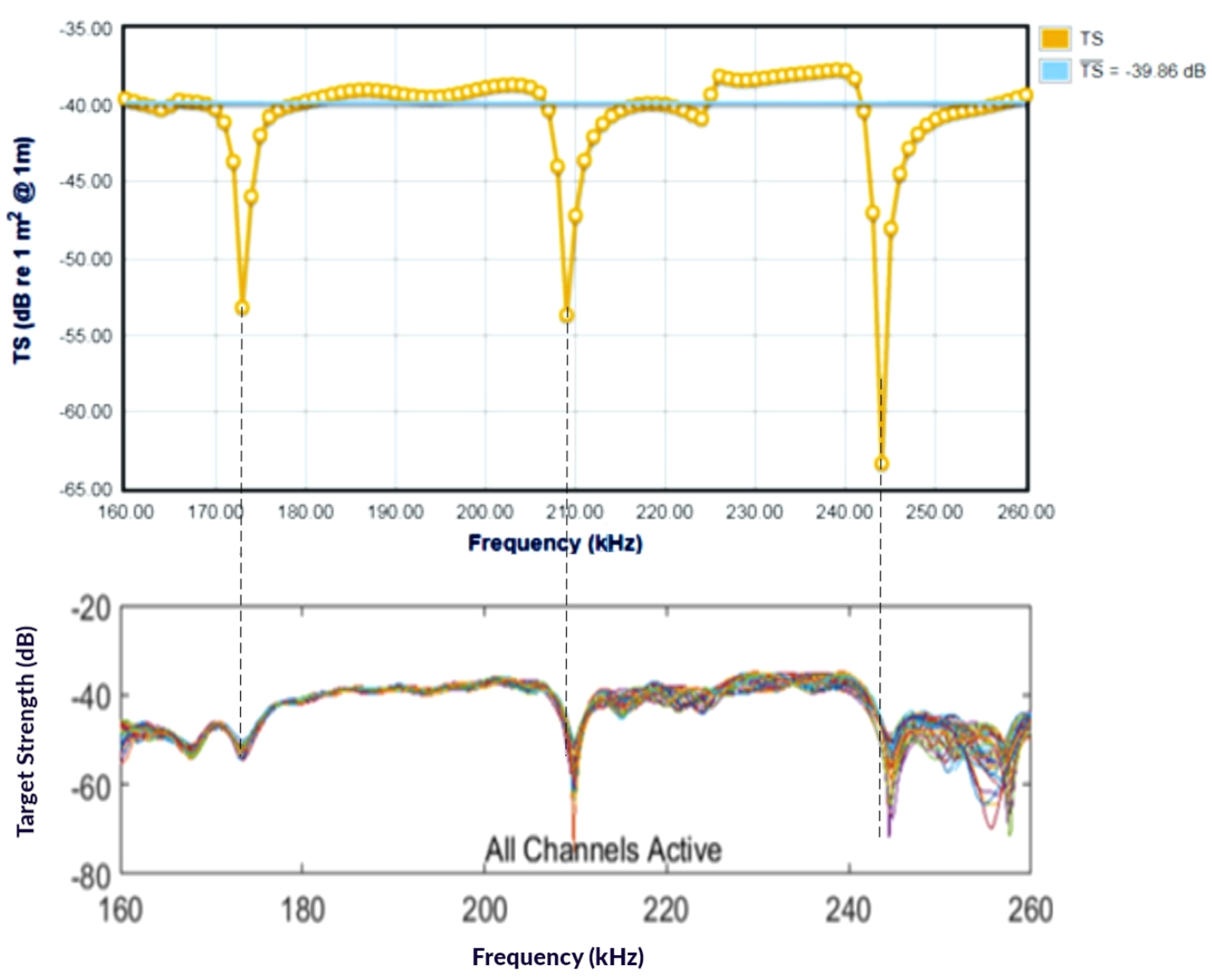

Figure 4. Comparison of $T S$ as a function of frequency based on (a) Sphere 38.1 ball model TS measurement by NOAA (source: https://swfscdata.nmfs.noaa.gov/AST/SphereTS/); and (b) Sphere 38.1 ball TS measurements carried out by ICES in research report \# 336 April 2017 using Simrad EK-80.

Table 2. Mean value of $T S$ samples of $F L=26 \mathrm{~cm}$ and tungsten carbide $38.1 \mathrm{~mm}$ with 9 treatments.

\begin{tabular}{||c|c|c|c|c|c|c||}
\hline \multirow{2}{*}{$\begin{array}{c}\text { Frequency } \\
(\mathrm{kHz})\end{array}$} & \multicolumn{2}{|c|}{ Bullet tuna } & \multicolumn{2}{c|}{ Bonito } & \multicolumn{2}{c|}{ Sphere } \\
\cline { 2 - 7 } & $T S$ & $S T D E V$ & $T S$ & $S T D E V$ & $T S$ & $S T D E V$ \\
\hline $160-170$ & -45.37 & 0.70 & -35.49 & 0.83 & -60.83 & 0.62 \\
$170-180$ & -43.17 & 1.22 & -41.85 & 1.00 & -45.13 & 1.81 \\
$180-190$ & -43.75 & 1.42 & -44.16 & 1.15 & -40.19 & 0.14 \\
$190-200$ & -43.85 & 1.24 & -43.76 & 1.20 & -44.60 & 0.68 \\
CW (200) & -45.55 & 2.25 & -33.50 & 0.00 & -38.89 & 0.00 \\
$200-210$ & -45.02 & 0.90 & -40.50 & 0.49 & -42.95 & 0.07 \\
$210-220$ & -46.70 & 1.71 & -43.12 & 1.73 & -44.93 & 0.02 \\
$220-230$ & -46.42 & 1.28 & -32.59 & 0.99 & -44.59 & 1.91 \\
$230-240$ & -47.97 & 0.75 & -51.49 & 2.24 & -60.39 & 0.17 \\
\hline
\end{tabular}

at frequency FM $160-170 \mathrm{kHz}$.

A simulation model of the $T S$ measurement using the sphereball WC measurement of $38.1 \mathrm{~mm}$ with the same physical parameters (Fig. 4(a)) showed up and down fluctuation patterns such as calibration measurements in situ conditions with an average $T S$ value stable at $-39.86 \mathrm{~dB}$. In Fig. 4(b), the pattern of fluctuating up and down measurements of ball TS of WC sphere 38.1 in controlled water conditions is shown. The two comparisons showed a pattern that was almost the same as the pattern of the spherical measurement fluctuations carried out. In this study we used $10 \mathrm{kHz}$ band. $T S$ value information with a narrower band range provided more extensive information than the wider band range.

The $T S$ value of the sphere ball calibration of the FM fre- quency for the range of $160-240 \mathrm{kHz}$ was relatively stable at $-42.5 \mathrm{~dB} \pm 1 \mathrm{~dB}$, with the exception at both ends of the 160 and 240 frequencies where it dropped, see Fig. 5. The average $T S$ for the bonito at a frequency range from FM $160-200 \mathrm{kHz}$, $\mathrm{CW} 200 \mathrm{kHz}$ to FM $200-240 \mathrm{kHz}$ were fluctuated from -47.95 to $-43.17 \mathrm{~dB}$. The pattern of the $T S$ response for $T S$ measurements of average bullet tuna with WC sphere calibration $T S$ is provided in Fig. 6. It was clear that the response pattern shown by the bullet tuna was relatively less fluctuated in comparison with the sphere in the given frequency range of $160-240 \mathrm{~Hz}$.

The $T S$ value of the average of bonito for each frequency range from FM $160-200 \mathrm{kHz}, \mathrm{CW} 200 \mathrm{kHz}$ to FM $200-$ $240 \mathrm{kHz}$ had no high $T S$ fluctuation value; that range from -51.49 to $-33.50 \mathrm{~dB}$. It is shown in Fig. 7 . The pattern fluctuation of the average $T S$ bonito rating on sphere ball calibration was almost the same except at FM frequency $160-170 \mathrm{kHz}$.

Pattern fluctuation of the average value of $T S$ for each frequency of FM $160-200 \mathrm{kHz}, \mathrm{CW} 200 \mathrm{kHz}$, up to $200-$ $240 \mathrm{kHz}$ for bullet tuna and bonito size $F L=26 \mathrm{~cm}$ can be regarded as a signature (fingerprint) of fish for that size. This signature can be used as important information in the process of fish identification and in the process of fish stock estimation. 


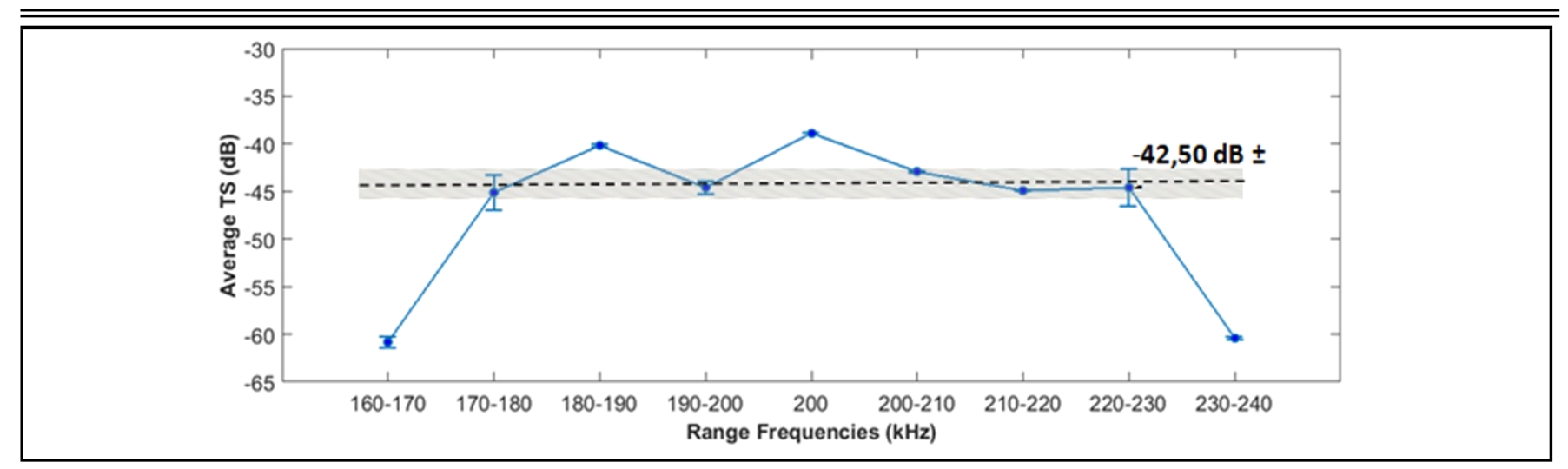

Figure 5. Average $T S$ value for measuring $38.1 \mathrm{~mm}$ tungsten carbide sphere calibration.

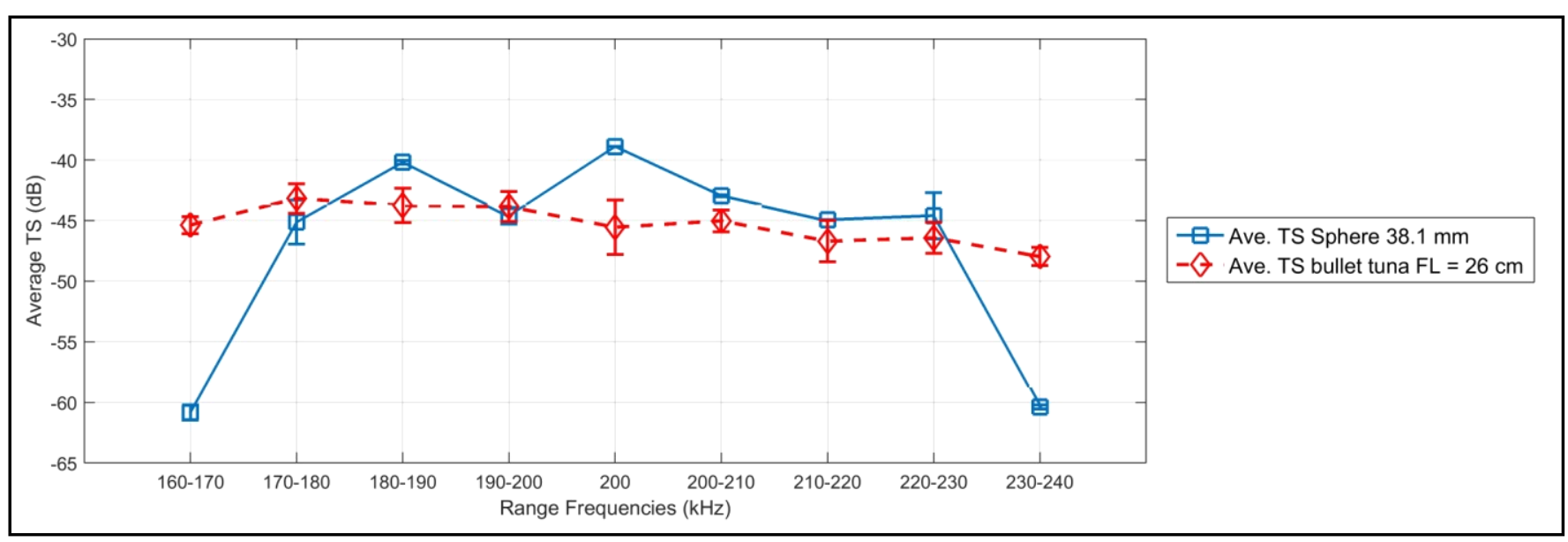

Figure 6. Graphic of comparison $T S$ bullet tuna $(F L=26 \mathrm{~cm})$ with $T S$ measurement of sphere ball calibration.

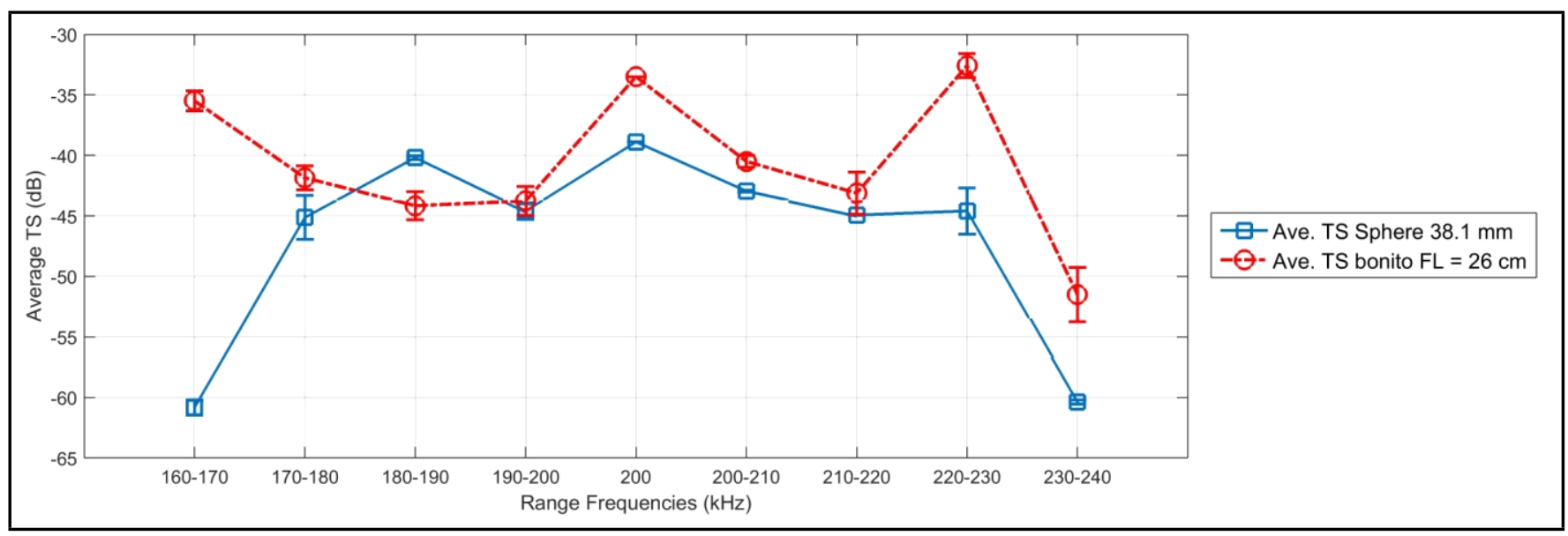

Figure 7. Graphic of comparison $T S$ bonito $(F L=26 \mathrm{~cm})$ with $T S$ measurement of sphere ball calibration.

\subsection{The Comparison of the $T S$ Values Between Bullet Tuna and Bonito of the Same Size}

According to Saanin ${ }^{18}$ and fishbase.org, bullet tuna and bonito in the classification arrangement are both included in the same family, namely Scombridae which has a cigar-shaped or torpedo body morphology but have a different genus for bullet tuna (genus: Auxis) and bonito (genus: Euthynnus). For both Auxis sp. and Euthynnus sp., they do not have any swim-bladder. The high difference of $T S$ values for both fish with $F L=26 \mathrm{~cm}$ size occurred at an FM frequency of $160-170 \mathrm{kHz}, \mathrm{CW} 200 \mathrm{kHz}$ and FM frequency $200-240 \mathrm{kHz}$ with range exceeded $\pm 3 \mathrm{~dB}$ (Fig. 8). The difference in mean values of $T S$ for the bullet tuna and bonito that occurred can be due to differences in the morphological shape of the two fish, see Fig. 9. Bullet tuna resembles a cigar where they are tapered at the tip of its mouth and the tip of its tail along the body extending from the head to tail (Figueiredo and Menezes, fishbase.org). ${ }^{19}$ The bonito also resembles a cigar with the tip of the mouth and tail tapered but with the mid-body slightly bulged/enlarged (Collette and Nauen, fishbase.org). ${ }^{20}$ 


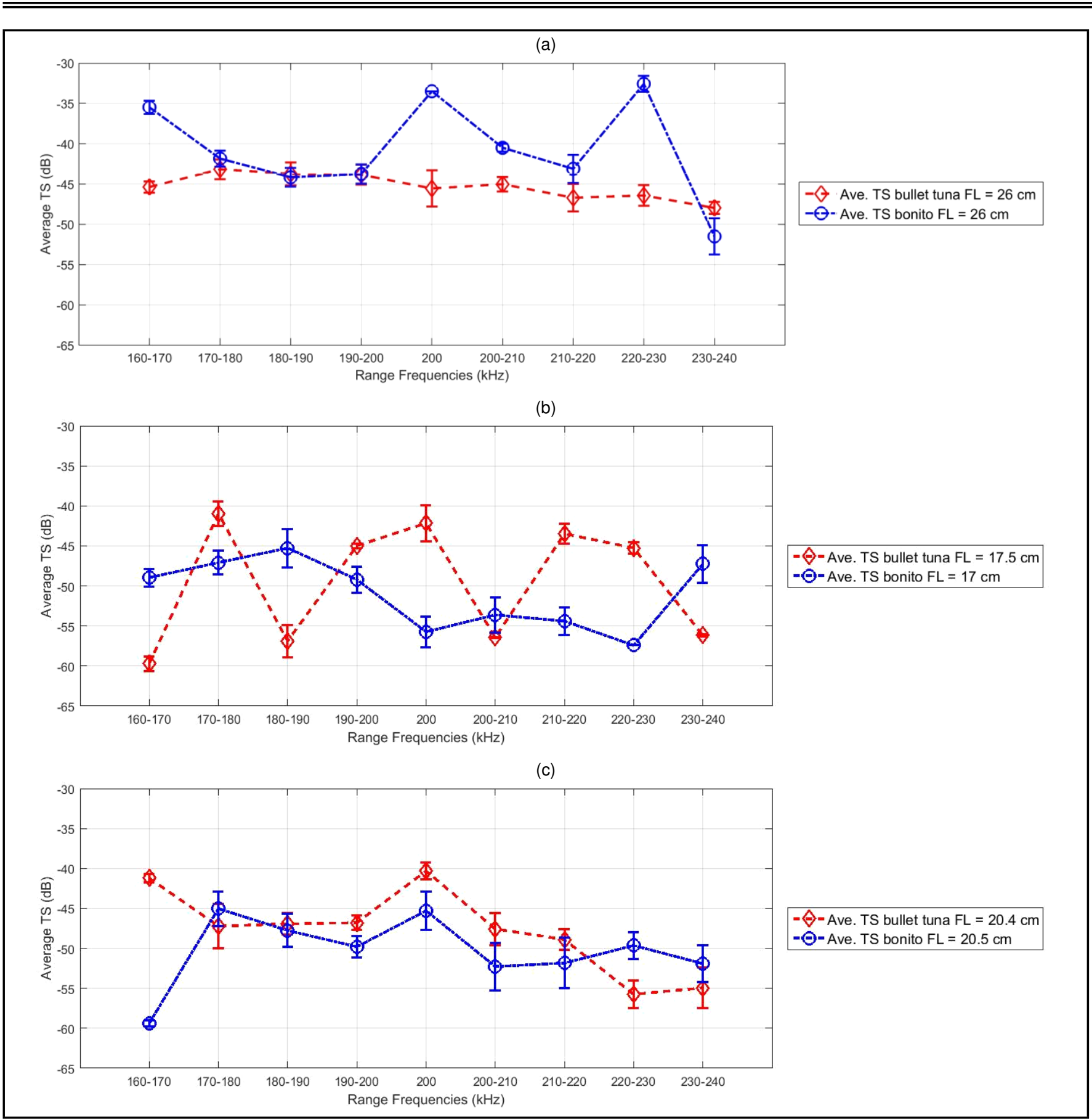

Figure 8. Graph of comparison of $T S$ value of average $T S$ between bullet tuna and bonito for $F L$ almost the same size: (a) both $F L=26 \mathrm{~cm}$; (b) bullet tuna $17.5 \mathrm{~cm}$ and bonito $17 \mathrm{~cm}$; then (c) bullet tuna $20.4 \mathrm{~cm}$ and bonito $20.5 \mathrm{~cm}$.

(a)

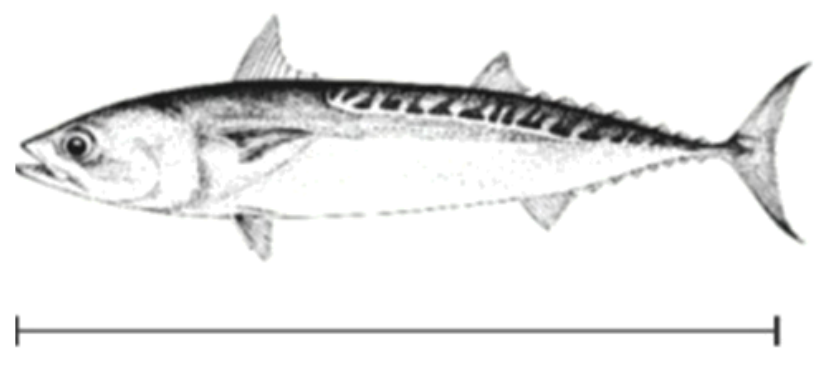

(b)

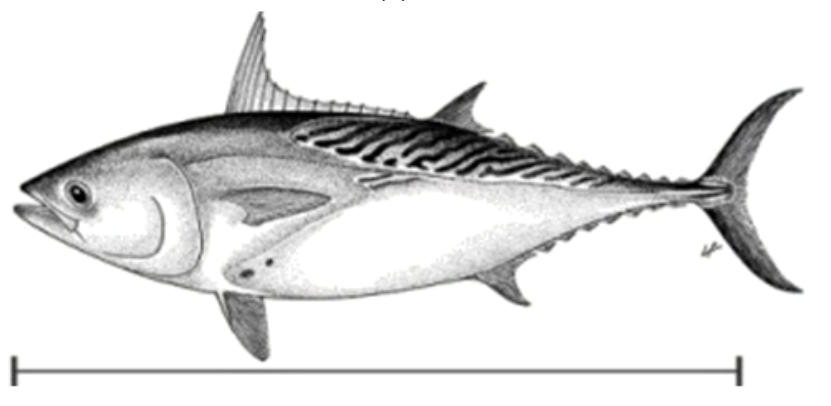

Figure 9. (a) Sketch drawing bullet tuna $F L=26 \mathrm{~cm}$; (b) Sketch drawing of bonito for $F L=26 \mathrm{~cm}$ (Source: fao.org). 


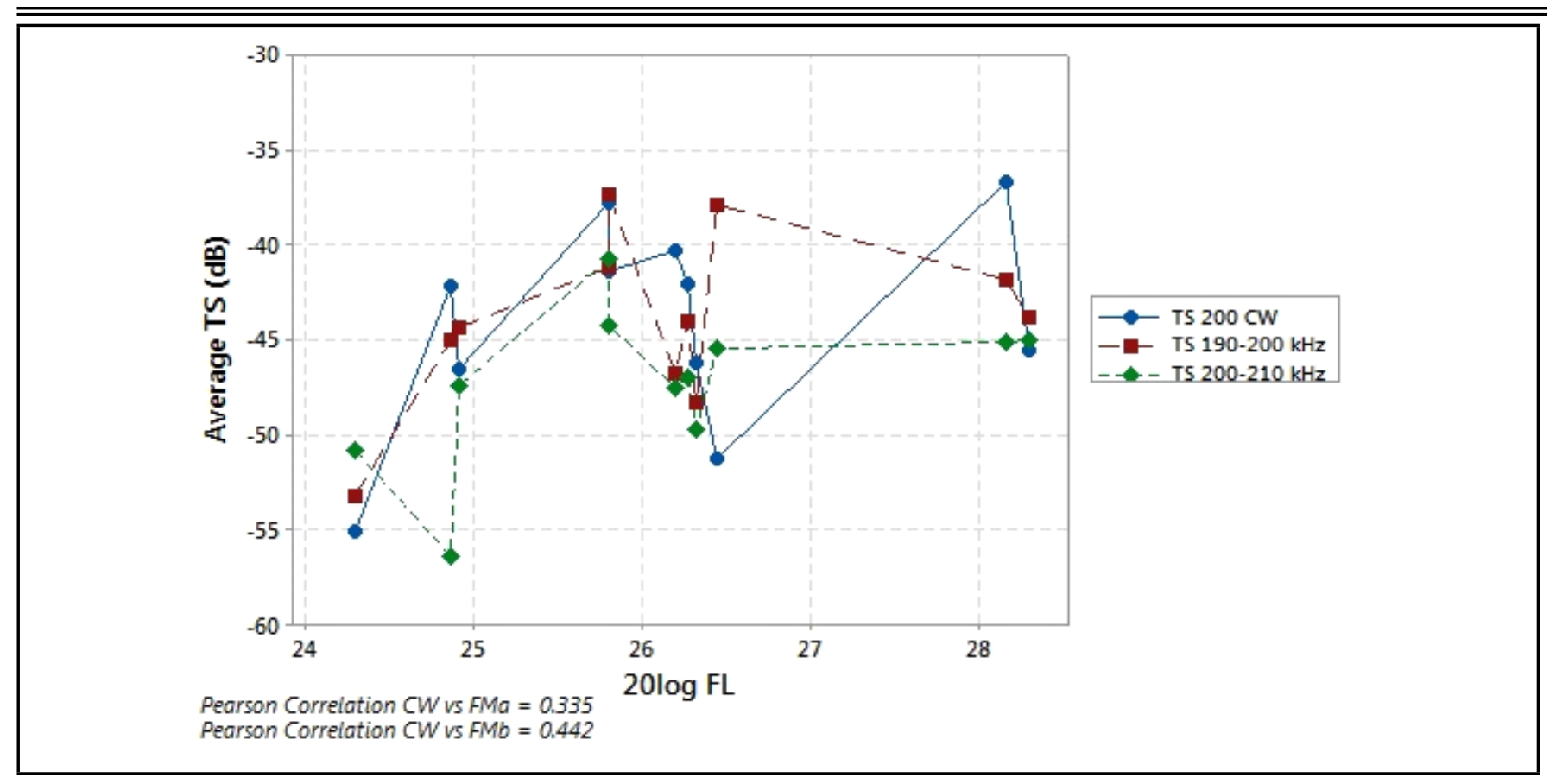

Figure 10. The correlation value of $T S$ CW $200 \mathrm{kHz}$ with $T S$ FMb (190-200 kHz) and TS CW $200 \mathrm{kHz}$ with TS FMa (200-210 kHz) for bullet tuna in the measured range of $F L$ size.

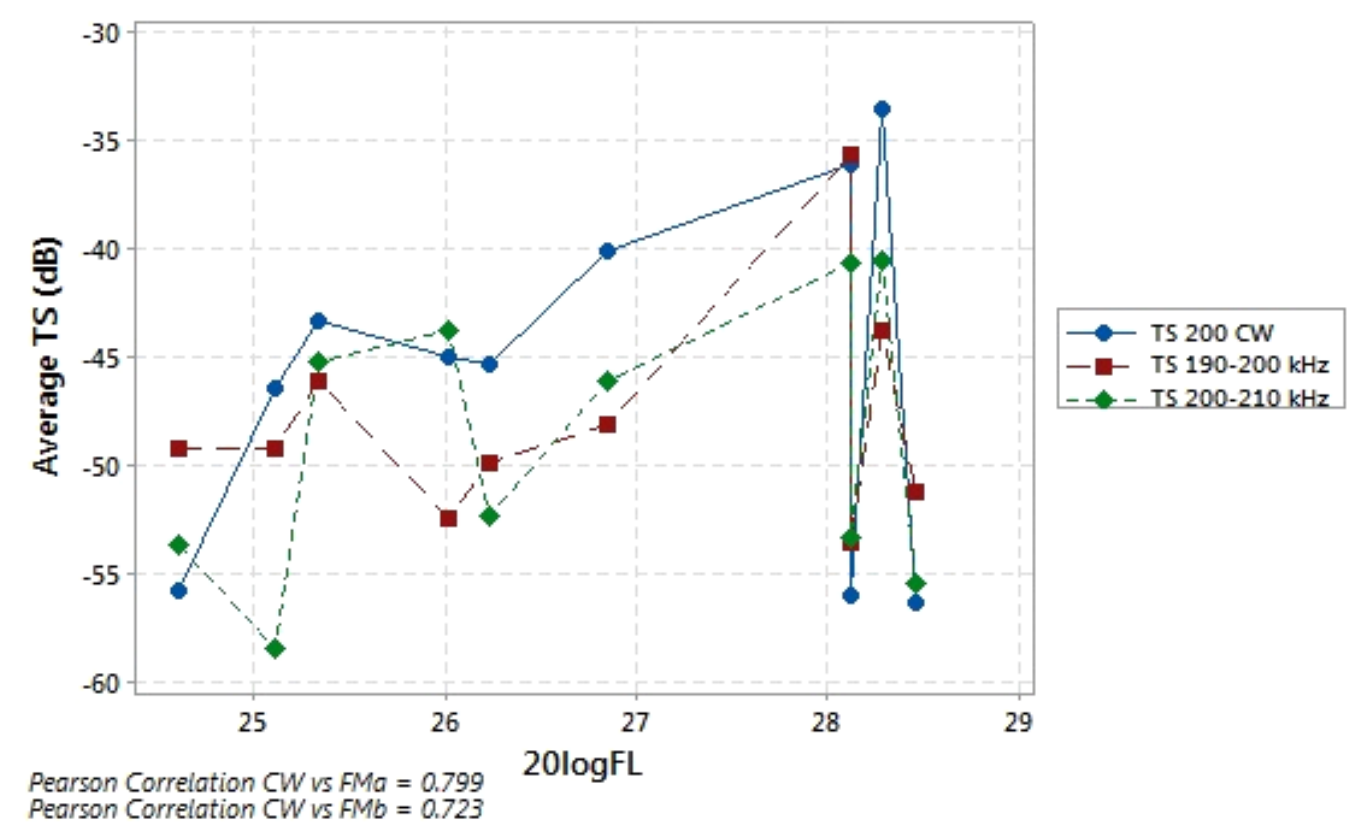

Figure 11. The correlation value of $T S$ CW $200 \mathrm{kHz}$ with $T S$ FMb (190-200 kHz) and TS CW $200 \mathrm{kHz}$ with $T S$ FMa (200-210 kHz) for bonito in the measured range of $F L$ size.

\subsection{The Comparison of the NB Approach vs the WB Approach for Both Species Sample}

The comparison of $T S$ values measured with NB approach (CW $200 \mathrm{kHz})$ with WB FMb $(190-200 \mathrm{kHz})$ and FMa $(200-210 \mathrm{kHz})$ was conducted to see whether the acoustic WB approach can be used to replace the NB approach in the $T S$ target measurements by looking at the magnitude of correlation of the TS CW $(200 \mathrm{kHz})$ with FMb and FMa. The value of the Pearson correlation on bullet tuna for $T S \mathrm{CW}$ with FMb was 0.34 , while for $T S \mathrm{CW}$ with FMa value was 0.42 for the $F L$ size range of $16.4-26 \mathrm{~cm}$ (Fig. 10). The Pearson correlation value for combo bonito for $T S \mathrm{CW}$ with $\mathrm{FMb}$ had a value of 0.72 , while the $T S \mathrm{CW}$ with FMa was a value of 0.80 using $\alpha=0.05$ for the $F L$ size range $17-26.5 \mathrm{~cm}$ (Fig. 11).

The $T S$ correlation value for bullet tuna was not significant because the value was smaller than 0.51 for the number of $n$ samples tested, whereas the correlation value for the bonito was greater than 0.51 for the sample being tested. The WB approach had a significant correlation with the NB approach so it can only be used for bonito for the size range $17-26.5 \mathrm{~cm}$. 


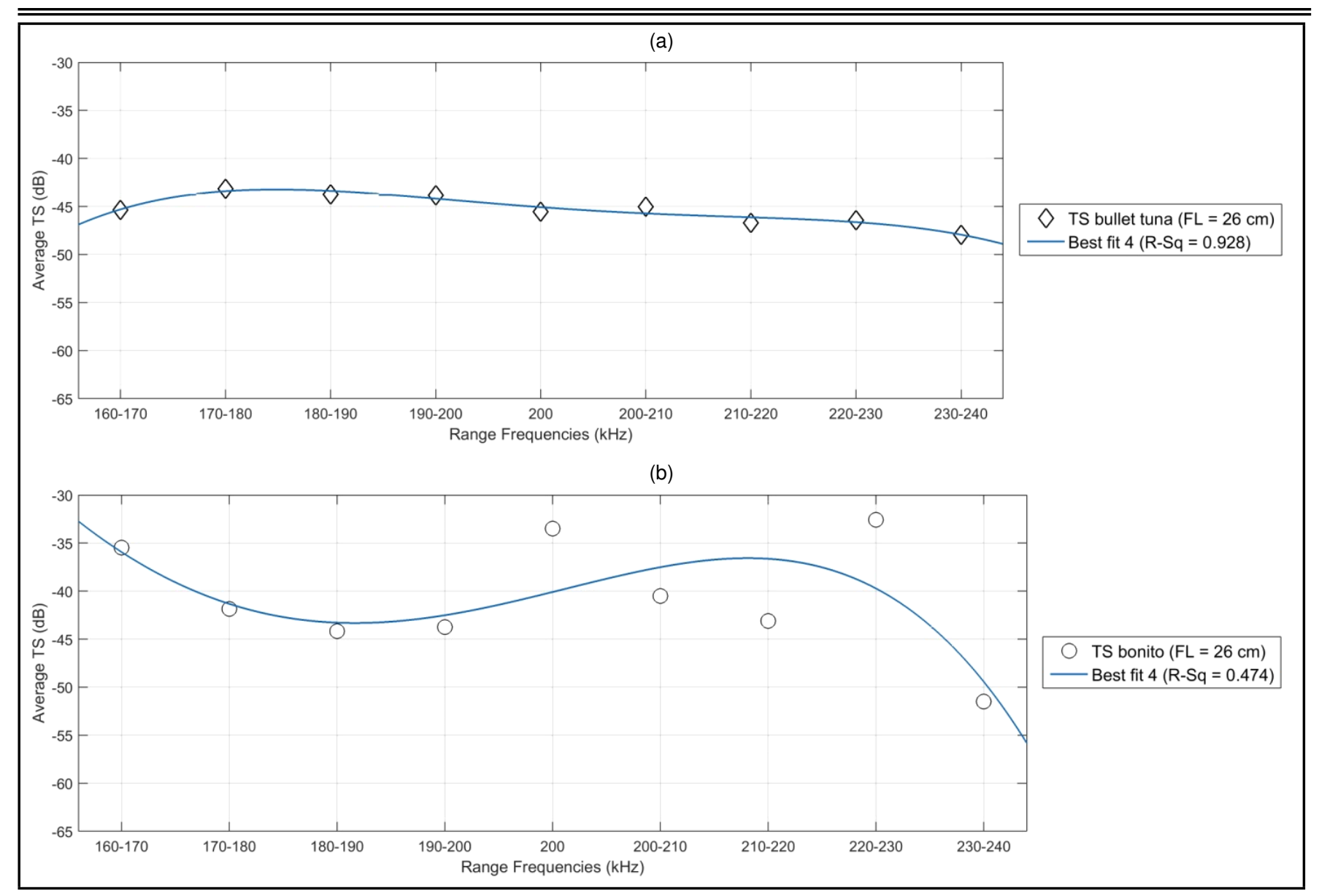

Figure 12. $T S$ response relationship to the frequency: (a) bullet tuna for the size of $F L=26 \mathrm{~cm}$; (b) bonito for size $F L=26 \mathrm{~cm}$.

Table 3. $R-s q$ value for $f(x) /$ best-fit of the target fish sample.

\begin{tabular}{|c|c|c|c|c|}
\hline Variable sample & \multicolumn{4}{|c|}{$R-s q$ value and best-fit degree } \\
\cline { 2 - 5 }$F L=26 \mathrm{~cm}$ & Degree 1 & Degree 2 & Degree 3 & Degree 4 \\
\hline Bullet tuna & 0.632 & 0.799 & 0.864 & 0.928 \\
Bonito & 0.054 & 0.085 & 0.468 & 0.474 \\
\hline
\end{tabular}

\subsection{The Relation Between the $T S$ and Frequency}

It is well understood that at very low frequencies, Rayleigh scattering applies and $\sigma_{b s}$ varies as $f^{4}$. Once the wavelength was commensurate with the target size, $\sigma_{b s}$ varies cyclically and smoothly at first, but extreme variations occurred at frequencies above a certain limit of $f_{1}$ (Simmond and MacLenan)..$^{5}$ In the high-frequency region, there were sharp maxima and minima corresponding to the resonance between the elastic vibration of the target and the sound field in the water. Resonance occurred at a discrete frequency that depended on the ratio of the sound-speed ratios. The calculation of the best-fit equation $f(x)$ to find out the response of the average $T S$ relationship of bullet tuna and bonito to the frequencies are provided in Fig. 12. The best-fit equations $f^{4}$ for bullet tuna are: $f(x)=-0.01461 x^{4}+0.3219 x^{3}-2.5 x^{2}+7.35 x-50.47$ with the value of $R-s q=0.93$, while bonito: $f(x)=$ $-0.01624 x^{4}+0.04563 x^{3}+1.85 x^{2}-11.02 x-26.79$ with $R-s q=0.47$ (Table 3 ). The relationship of the $T S$ response to frequencies for bullet tuna was more significant than that of bonito ( $R-s q$ bullet tuna $>R-s q$ bonito).

\section{CONCLUSIONS}

(1) In the case of bonito, the NB and WB can both be used because there were no $T S$ value differences, and there was a high significant correlation; whereas in the case of bullet tuna, the use of WB cannot be represented by NB because it had a low significant Pearson correlation value.

(2) The relationship of $F L$ and $T S$ to frequency on WB fluctuated and indicated the frequency fourth power dependence $\left(f^{4}\right)$ as the best-fit equation.

\section{ACKNOWLEDGEMENTS}

The data provided in this paper were the results from a joint research collaboration between BPPL-KKP and ITK-IPB under the research project "Measurement of Target Strength Characteristics and TS-Length Formulation on Fish Key Indicators for Improving Accuracy of Fish Stock Estimation 2016."

\section{REFERENCES}

1 Goddard, G. C. and Welsby, V. G. Statistical measurement of the acoustic target strength of live fish, Memorandum No. 456, University Birmingham, Dept. of Electronic \& Electrical Eng., (1975).

2 Johanesson, K. A. and Mitson, R. B. Fisheries acoustic a practical manual for acoustic biomass estimation, FAO Fisheries Technical Paper, Rome, (1983). 
${ }^{3}$ Harbitz, A., Ona, E., and Pennington, M. The use of an adaptive acoustic-survey design to estimate the abundance of highly skewed fish populations, ICES Journal of Marine Science, 66, 1349-1354, (2009). https://dx.doi.org/10.1093/icesjms/fsp088

${ }^{4}$ FAO/SEAFDEC, Improvement of fishery data and information collection systems in Southeast Asia, Proc. the FAO/SEAFDEC Regional Workshop on the Improvement of Fishery Data and Information Collection Systems, Bali, Indonesia, (2005).

${ }^{5}$ Simmonds, E. J. and MacLennan, D. N. Fisheries Acoustics: Theory and Practice, 2nd edition, Blackwell Publishing, Oxford, (2005).

${ }^{6}$ Holliday, D. V. Resonance structure in echoes from schooled pelagic fish, Journal of the Acoustical Society of America, 51, 1322-1332, (1972). https://dx.doi.org/10.1121/1.1912978

7 Foote, K. G., Knudsen, H. P., Korneliussen, R. J., Nordb $\varnothing$, P. E., and Røang, K. Postprocessing system for echo sounder data, Journal of the Acoustical Society of America, 90, 37-47, (1991). https://dx.doi.org/10.1121/1.401261

${ }^{8}$ Korneliussen, R. J. and Ona, E. An operational system for processing and visualizing multi-frequency acoustic data, ICES Journal of Marine Science, 59, 293-313, (2002). https://dx.doi.org/10.1006/jmsc.2001.1168

9 Scoulding, B., Chu, D., Ona, E., and Fernandes, P. G. Target strengths of two abundant mesopelagics fish species, Journal of the Acoustical Society of America, 137, 989-1000, (2015). https://dx.doi.org/10.1121/1.4906177

${ }^{10}$ Foote, K. G, Atkins, P. R., Francis, D. T. I., and Knutsen, T. Measuring echo spectra of marine organisms over a wide bandwidth, Proc. International Conference on Underwater Acoustic Measurements: Technologies and Results, II, 501-508, Heraklion, Greece, (2005).

11 Stanton, T. K., Chu, D., Jech, J. M., and Irish, J. D. New broadband methods for resonance classification and high-resolution imagery of fish with swimbladders using a modified commercial broadband echo sounder, ICES Journal of Marine Science, 67, 365-378, (2010). https://dx.doi.org/10.1093/icesjms/fsp262
${ }^{12}$ Simmonds, E. J. and Armstrong, F. A wideband echo sounder: measurements on cod, saithe and herring, and mackerel from 27 to $54 \mathrm{kHz}$, Rapports et Procès-Verbaux des Réunions, 189, 381-387, Conseil International pour l'Exploration de la Mer, (1990).

13 Stanton, T. K., Chu, D., Wiebe, P. H., Martin, L., and Eastwood, R. L. Sound scattering by several zooplankton groups I: Experimental determination of dominant scattering mechanisms, Journal of the Acoustical Society of America, 103, 225-235, (1998). https://dx.doi.org/10.1121/1.421469

14 Thompson, C. H. and Love, R. H. Determination of fish size distributions and areal densities using broadband low-frequency measurements, ICES Journal of Marine Science, 53, 197-201, (1996). https://dx.doi.org/10.1006/jmsc.1996.0022

15 Zakharia, M. E., Megand, F., Hetroit, F., and Diner, N. Wideband sounder for fish species identification at sea, ICES Journal of Marine Science, 53, 203-208, (1996). https://dx.doi.org/10.1006/jmsc.1996.0023

${ }^{16}$ Lavery, A. C., Bassett, C., Lawson, G. L., and Jech, M. J. Exploiting signal processing approaches for broadband echosounders, ICES Journal of Marine Science, 74 (8), 2262-2275, (2017). https://dx.doi.org/10.1093/icesjms/fsx155

${ }^{17}$ Setiawan, W., Jaya, I., Pujiyati, S., Hestirianoto, T., Priatna, A., and Ma'mun A. Empirical acoustic TS - Length relationship for Torpedo Scad (Megalaspis cordyla), IOP Conference Series: Earth and Environmental Science, 176, 012031, (2018). https://dx.doi.org/10.1088/1755$1315 / 176 / 1 / 012027$

18 Saanin, H. Taksonomi dan Kuntji Identifikasi Ikan I dan II, Bandung, Indonesia, (1968).

${ }^{19}$ Figueiredo, J. L. and Menezes, N. A. Manual de Peixes Marinhos do Sudeste do Brasil, VI. Teleostei, Museu de Zoologia, Universida de São Paulo, Brazil, (2000).

${ }^{20}$ Collette, B. B. and Nauen, C. E. FAO Species Catalogue. Vol. 2. Scombrids of the world. An annotated and illustrated catalogue of tunas, mackerels, bonitos and related species known to date, FAO Fisheries Synopsis, 125 (2), Rome, (1983). 